\title{
Sintering Trajectories: Description on How Density, Surface Area, and Grain Size Change
}

\author{
RANDALL M. GERMAN ${ }^{1,2}$ \\ 1.-College of Engineering, San Diego State University, San Diego, CA, USA. 2.—e-mail: randgerman@ \\ gmail.com
}

Sintering is a mainstay production step in forming metal, ceramic, polymer, and composite components from particles. Since the 1940s, the sintering process is treated using a matrix of mathematical relationships that include at least seven atomic transport mechanisms, several options on powder characteristics, and three pore-grain morphology options. The interplay of these relationships is handled by numerical solutions to predict property development. An alternative approach is to track the sintering trajectory using relatively simple relationships based on bulk measures. Energy minimization dictates that initial stage sintering acts to reduce surface area. In late stage sintering, the energy minimization turns to grain boundary area reduction via grain growth. Accordingly, relationships result between density, surface area, and grain size, which largely ignore mechanistic details. These relationships are applicable to a wide variety of materials and consolidation conditions, including hot pressing, and spark sintering.

\section{INTRODUCTION}

Sintering reduces surface area by growing bonds between contacting particles during heating. Due to random orientations for the particles, the bond forms with an embedded grain boundary accommodating the crystal misorientation between particles. Effectively, early sinter bonding replaces surface area with lower energy grain boundary area. As surface area is annihilated the driving force declines, resulting in slower sintering rates. ${ }^{1}$ Bond size between particles is one monitor of sintering; however, it is a tedious measure, especially for small particles. On the other hand, density, surface area, shrinkage, and properties (hardness and strength) are measures that average over many particleparticle bonds. These attributes are easier to measure and follow trajectories that require only a few experiments to map the sintering process. ${ }^{2}$

Several mass transport mechanisms act during sintering, broadly characterized as either-

- surface transport (surface diffusion and evaporation-condensation), or

- bulk transport (grain boundary diffusion, plastic flow, dislocation climb, viscous flow, and volume diffusion).
Bulk transport processes contribute to densification, but surface transport only gives bonding. Early sintering initiates bonding by surface transport, but as surface area is converted into grain boundary area the opportunity for densification increases. Small particles, longer sintering times, and higher sintering temperatures increase sintering densification and improve properties. For example, traditional ferrous powder metallurgy relies on nominally 100 $\mu \mathrm{m}$ particles compacted to $85-90 \%$ density, followed by sintering for up to $30 \mathrm{~min}$ at $1120^{\circ} \mathrm{C}$. This combination minimizes densification to avoid component warpage that would arise from the density gradients induced by uniaxial compaction. Alternatively, powder injection molding (PIM) relies on binder-assisted hydrostatic forming using $5-\mu \mathrm{m}$ particles sintered at higher temperatures $\left(1250^{\circ} \mathrm{C}\right)$ for longer times (120 min). The $60 \%$ dense PIM shape densifies to about $98 \%$ density, with isotropic shrinkage to avoid distortion. Sintered properties reflect the density difference. For example, after heat treatment, a Fe$2 \mathrm{Ni}-0.5 \mathrm{C}$ steel delivers $650 \mathrm{MPa}$ yield strength by conventional powder metallurgy, but $1230 \mathrm{MPa}$ by injection molding. This strength difference comes from the higher density attained with the smaller particles, higher temperature, and longer time. 


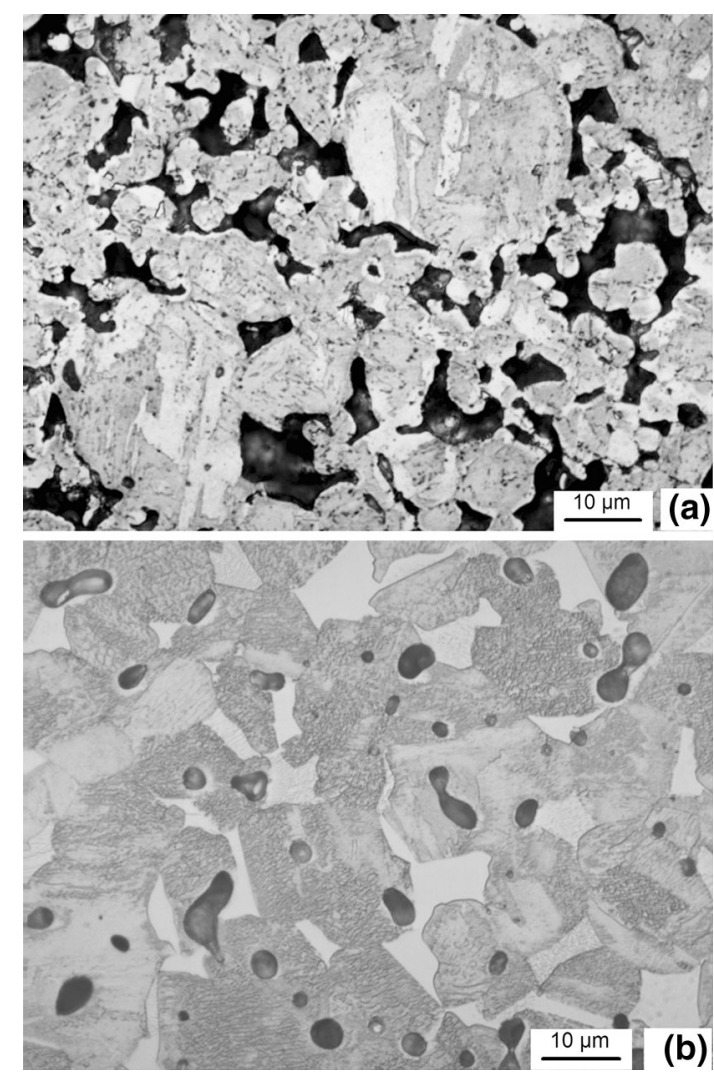

Fig. 1. Cross-section micrographs of 17-4 PH stainless steel powder during heating to (a) $1100^{\circ} \mathrm{C}$ or (b) $1300^{\circ} \mathrm{C}$. The pores are transparent due to the clear plastic used to prevent distortion during polishing.

Energy reduction helps understand sintering. Contrast the images in Fig. 1; both were taken by quenching injection molded 17-4 $\mathrm{PH}$ stainless steel compacts during heating. ${ }^{3}$ As sintering progresses, surface area declines while density increases, in this case from $73 \%$ to $91 \%$. Grain boundaries form in the contacts, and over time grain size increases with densification while surface area declines. Density, surface area, and grain size are useful sintering metrics, since there is a natural trajectory evident over a range of materials, particle sizes, and processing techniques. ${ }^{4-8}$ Crystalline materials first give up surface area to form grain boundaries at the interparticle bonds. Late in sintering, grain growth removes grain boundary area as densification continues. Accordingly, grain boundary area increases, peaks, and then declines during sintering. Strength depends on both density and grain size, so oversintering with a loss of strength occurs with longer hold times or higher sintering temperatures.

\section{ENERGY REDUCTION}

Sintering reduces energy by elimination of surface area due to bond growth, partially offset by a concomitant increase in grain boundary area and energy. Both aspects are linked to density. DeHoff et al. $^{9}$ proposed a linear relationship between surface area and sintered density, assuming densification work was derived from the surface energy release. A similar conceptualization is embedded in treatments of sintering by viscous flow ${ }^{10}$ and grain boundary diffusion. ${ }^{11}$

Late in sintering, surface area loss is slow, but grain coalescence continues to reduce grain boundary area. Sensibly, an energy cascade occurs. First, solid-vapor energy is converted into grain boundary energy by bond growth. Subsequently, grain boundary energy is eliminated by grain growth. The details of the sintering trajectory depend on the relative surface transport and bulk transport rates. Some cases lose surface area without densification, such as boron sintering in vacuum ${ }^{12}$ or zirconia sintering in hydrogen chloride, ${ }^{13}$ others lose surface area with some densification such as alumina in argon $^{14}$ or iron in hydrogen, ${ }^{15}$ while yet others sinter with considerable densification such as copper in hydrogen ${ }^{16}$ or urania in hydrogen. ${ }^{17}$ In all cases involving densification, surface area declines in proportion to the gain in density.

\section{SURFACE AREA: DENSITY TRAJECTORY}

Surface area is a means to track energy release during sintering. Measures are either area per unit mass or per unit volume. Surface area per unit mass, specific surface area, is measured by gas absorption or fluid permeability. These measures only access open pores, so sealed internal pores are not included in the specific surface area, $S_{\mathrm{M}}$. Common units are $\mathrm{m}^{2} / \mathrm{g}$ or $\mathrm{cm}^{2} / \mathrm{g}$. The absorption or permeability measurements are effective up to pore closure at fractional densities typically from 0.90 to 0.95 .

On the other hand, quantitative microscopy measures the surface perimeter on two-dimensional cross-sections, giving the volume-based surface area, $S_{\mathrm{V}}$. Convenient units are $\mathrm{m}^{2} / \mathrm{m}^{3}$ or $\mathrm{cm}^{2} / \mathrm{cm}^{3}$ (inverse length). Volume-based surface area includes both open and closed pores. Prior to pore closure the conversion from one measure to the other is straightforward based on the sintered density $\rho_{\mathrm{S}}$ :

$$
S_{\mathrm{M}}=\frac{S_{\mathrm{V}}}{\rho_{\mathrm{S}}}
$$

Sintered density is related to fractional density $\rho_{\mathrm{S}}=\rho_{\mathrm{T}} f$, with $f$ being the fractional density and $\rho_{\mathrm{T}}$ being the theoretical density for the material.

Several studies have confirmed that specific surface area depends on sintered density. $4,5,9,15,18-22$ Figure 2 illustrates such behavior using data for urania $\left(\mathrm{UO}_{2}\right)$ sintering at $1500^{\circ} \mathrm{C}$ for up to 2000 min. ${ }^{19}$ The specific surface area is given relative to the starting surface area versus fractional density with a straight line fit to the data. The surface area approaches zero at about $10 \%$ porosity, indicating that only closed pores remain. 
relative surface area

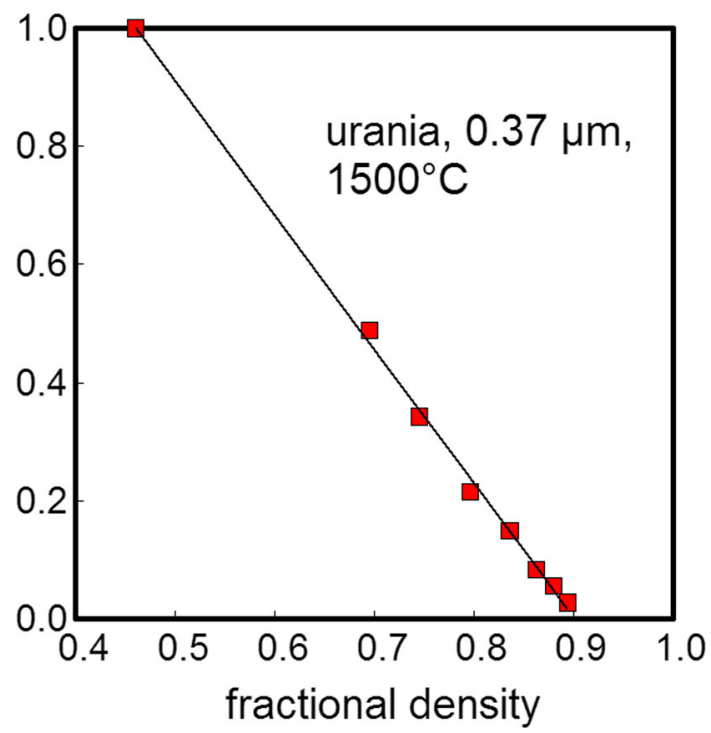

Fig. 2. Surface area (normalized to the starting powder surface area) versus fractional density for urania sintering at $1500^{\circ} \mathrm{C}^{17}$

As another example, Fig. 3 plots the surface area for 170-nm alumina $\left(\mathrm{Al}_{2} \mathrm{O}_{3}\right)$ during sintering at $1325^{\circ} \mathrm{C}^{5}$ Again a linear decline in surface area accompanies densification.

During sintering the specific surface area $S_{\mathrm{M}}$ falls from its initial value $S_{O}$ as the fractional sintered density $f$ increases: ${ }^{1}$

$$
\frac{S_{\mathrm{M}}}{S_{\mathrm{O}}}=a-b f
$$

The constants $a$ and $b$ depend on the powder. Spherical PIM powder with an initial fractional density of 0.64 would give $a=3.3$ and $b=3.6$.

A favorite metric for sintering is shrinkage, $Y$, defined as the change in component size divided by the initial size, or $\Delta L / L_{\mathrm{O}}$. By convention, a decrease in component size is positive shrinkage (effectively, a negative dimensional change is the shrinkage). Nearly isotropic shrinkage occurs in PIM components. In those cases, shrinkage links the sintered fractional density $f$ to the green fractional density $f_{\mathrm{O}}$ as,

$$
f=\frac{f_{\mathrm{O}}}{(1-Y)^{3}}
$$

Accordingly, dilatometer-measured shrinkage provides a means to assess density during heating. Related models link shrinkage to other sintering metrics. ${ }^{18}$ Using volume conservation calculations, independent of the atomic transport mechanism, the normalized surface area $S_{\mathrm{M}} / S_{\mathrm{O}}$ links to fractional density. ${ }^{1}$ Figure 4 plots the results from this approach for starting densities of $0.50,0.55,0.60$, and 0.65 . No sintering mechanism is invoked, simply geometric parameters are employed to link surface area to densification.

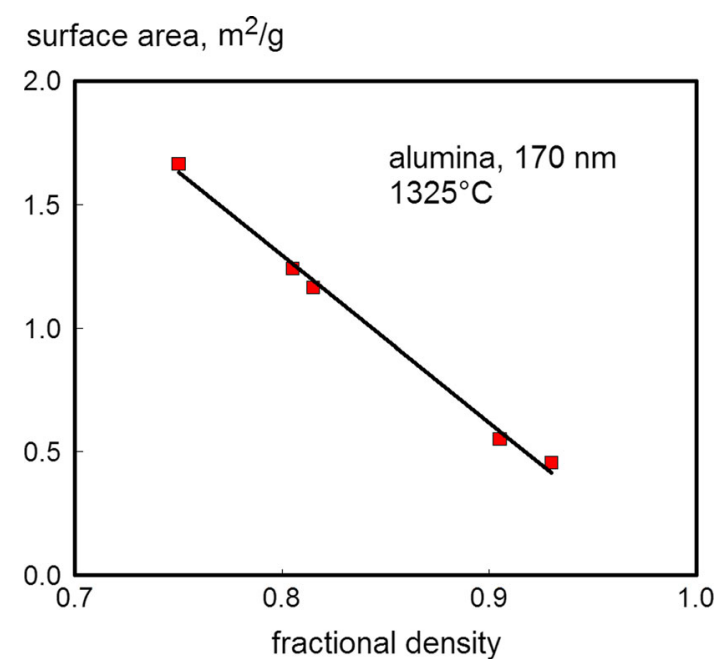

Fig. 3. Specific surface area versus fractional density for $170 \mathrm{~nm}$ alumina sintering at $1325^{\circ} \mathrm{C}^{5}$

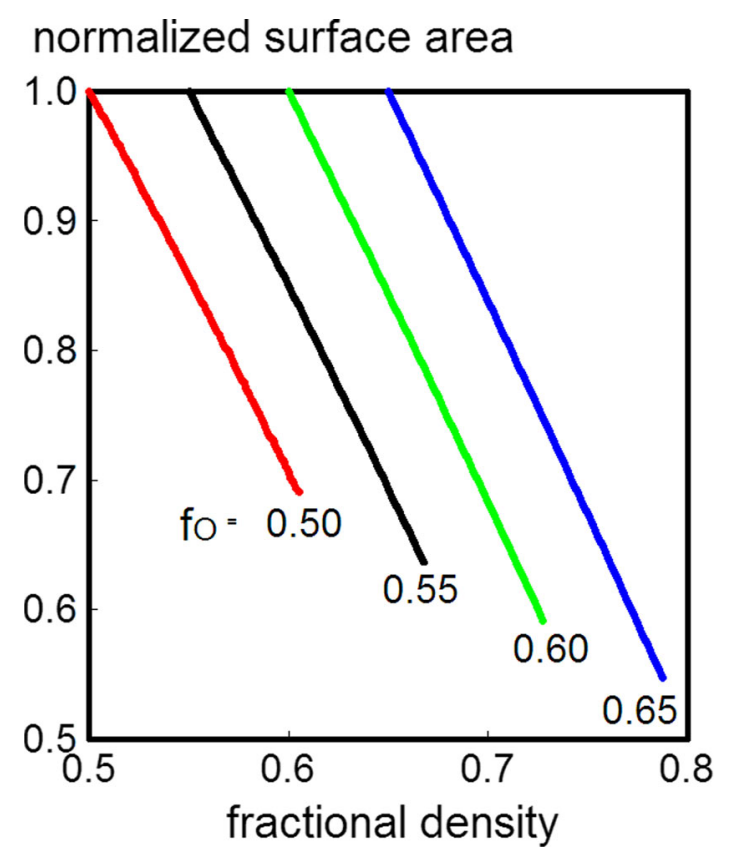

Fig. 4. Geometric volume conservation calculations for surface area versus sintered density for spherical particles with starting fractional densities $\left(f_{\mathrm{O}}\right)$ of $0.50,0.55,0.60$, or $0.65 .^{1}$

Other studies verify this behavior. Figure 5 compares the surface area-density trajectory for 0.55 starting density using several studies. The plot from Fig. 4 is labeled as the "geometric" line. For comparison, Hare ${ }^{23}$ simulated three-dimensional spherical particle sintering, providing results independent of the diffusion process. The "computer" specific surface area change with density is included for a starting green density of 0.55 . Also shown are the "experimental" results from $1050^{\circ} \mathrm{C}$ copper sintering reported by DeHoff et al., "s "shrinkage" calculations by Kumar, ${ }^{24}$ and "energy" reduction calculations. ${ }^{1}$ Similar relationships emerge from these different approaches. 
normalized surface area

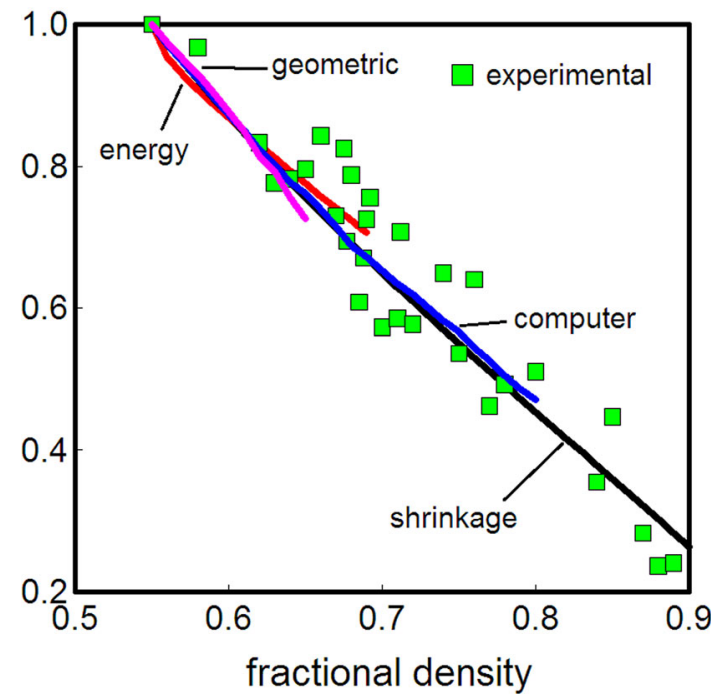

Fig. 5. A comparison of the "geometric" relationship from Fig. 4 at 0.55 starting density and other approaches to the surface area loss during densification; included are calculations based on "energy" minimization, ${ }^{1}$ "shrinkage" models, ${ }^{24}$ "computer" simulations, ${ }^{23}$ and "experimental" copper data. ${ }^{9}$

Since surface transport controlled sintering reduces surface area without densification, the surface area trajectory helps identify surface diffusion versus grain boundary diffusion. Figure 6 shows surface area versus density from constant heating rate experiments on $140-\mathrm{nm}$ alumina starting at 0.32 fractional green density. ${ }^{14}$ Compacts were extracted at $50^{\circ} \mathrm{C}$ intervals between $900^{\circ} \mathrm{C}$ and $1300^{\circ} \mathrm{C}$. The trajectory sits between that expected for sintering by grain boundary diffusion and surface diffusion. Surface diffusion is the dominant process, accounting for about $80 \%$ of the surface area loss. As surface area is annihilated and grain boundary area is created, the dominant process shifts to grain boundary diffusion.

\section{GRAIN BOUNDARY AREA}

Surface area is an effective monitor for sintering. However, the loss of surface area (energy) is offset by the growth of grain boundary area (energy); subsequently, grain growth acts to remove grain boundary area. For polycrystalline particles, initial grain growth is rapid until the grain size reaches the particle size, but then slows in the presence of pores. ${ }^{8}$

Two coarsening options operate while pores exist. The first is when the vapor phase in the pores is inactive, corresponding to most sintering practice. Grain growth then depends on transport across the solid-solid interface at the grain contacts. The second case is when the pores contain an active vapor phase, providing evaporation-condensation transport across pores. This occurs with halidedoped atmospheres or in systems sensitive to oxygen or water partial pressures.

\section{normalized surface area}

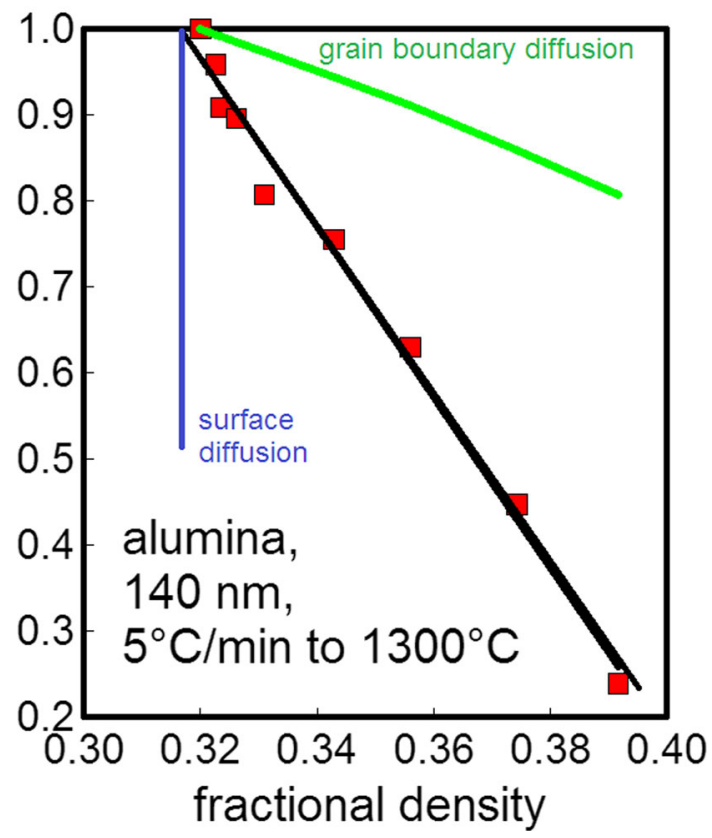

Fig. 6. Constant heating rate data for 140-nm alumina powder giving normalized specific surface versus sintered density. ${ }^{14}$ The behavior expected for pure bulk and surface transport sintering are given for comparison.

Grain growth in sintering results in the median grain volume $\left(G^{3}\right)$ increasing linearly with heating time: ${ }^{8}$

$$
G^{3}=G_{\mathrm{O}}^{3}+K t
$$

Here, $G$ is the grain size and the starting grain volume is $G_{\mathrm{O}}^{3}$ (often ignored), hold time is $t$, and $K$ is the temperature-dependent rate parameter. As a demonstration, grain size data are plotted in Fig. 7 for copper at $900^{\circ} \mathrm{C},{ }^{16}$ nickel at $900^{\circ} \mathrm{C},{ }^{25}$ and iron at $850^{\circ} \mathrm{C}^{15}$ on a log-log basis. Plotting this way ignores the initial grain volume, but at longer times the $G_{\mathrm{O}}^{3}$ term is insignificant. The lines correspond to a slope of one-third while the individual size measures are shown as symbols. The fit to Eq. 4 is evident.

For a single phase solid undergoing sintering, the grain growth rate parameter reflects two factors: the mass transport rate across the grain boundaries and the mass transport rate in the vapor phase. The relative solid-solid interface area is measured by the contiguity $C_{\mathrm{SS}}$ giving: ${ }^{8}$

$$
K=C_{\mathrm{SS}} K_{\mathrm{SS}}+\left(1-C_{\mathrm{SS}}\right) K_{\mathrm{SV}}
$$

where $K_{\mathrm{SS}}$ is the grain growth rate parameter associated with grain boundaries and $K_{\mathrm{SV}}$ corresponds to the solid-vapor interface. Contiguity is the fraction of the grain perimeter consisting of solid-solid contacts. It is initially zero so early grain growth depends only on the solid-vapor contribution. As grain boundary area increases during sintering, the rate parameter converges to $K_{\mathrm{SS}}$, the 
solid-solid behavior. As noted above, the solidvapor surface area is a linear function of the fractional density. Accordingly, Table I captures relationships between fractional density, grain coordination number, contiguity, and pore size. ${ }^{26}$ Note that for these conditions the contiguity is related to the square-root of the fractional porosity. Pores generally retard grain growth, but as pores are annihilated during sintering, grain size rapidly enlarges.

\section{GRAIN SIZE TRAJECTORY}

Porosity and grain size are related during sintering, although grain growth continues even after pore elimination. While pores remain, the mean grain size tracks with fractional porosity, as illustrated in Fig. 8. This plot compares copper data ${ }^{16}$ with the inverse square-root relationship first proposed by Bruch; ${ }^{27}$

$$
G=\theta \frac{G_{\mathrm{O}}}{\sqrt{\varepsilon}}
$$

where $G_{\mathrm{O}}$ is the initial grain size, $\varepsilon$ is fractional porosity $(\varepsilon=1-f)$, and $\theta$ reflects the starting grain size and porosity condition and is often is near 0.6.

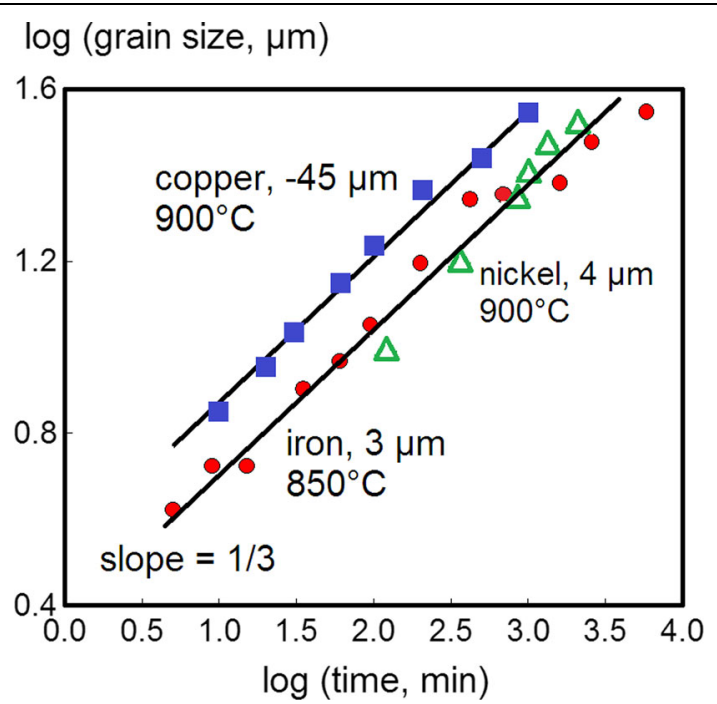

Fig. 7. Log-log plot of grain size versus sintering time for copper, ${ }^{16}$ nickel, ${ }^{25}$ and iron ${ }^{15}$ with indicated slopes of one-third.
Figure 9 offers examples taken during sintering 4and $0.1-\mu \mathrm{m}$ iron, ${ }^{28} 8$-nm zirconia, ${ }^{29} 25-\mu \mathrm{m}$ stainless steel ${ }^{30}$ and $0.1-\mu \mathrm{m}$ alumina. ${ }^{31}$ Results from other studies, even hot pressing and field-assisted or spark sintering experiments, follow Eq. 6 . $^{8}$ Hence, grain size and fractional density are related during sintering, with grain size increasing rapidly as pores are eliminated.

Energy reduction during sintering leads to a competition within a sintering structure ${ }^{1,9,31}$ Bond growth is initially dominant while the grain boundary area is small. Grain growth relies on grain boundary formation in the bonds between contacting grains. Late in a sintering grain growth acts to eliminate grain boundary area and becomes a dominant aspect of sintering. From a few experiments, it is possible to link the key sintering parameters. For example, knowing the time-temperature required to reach final density allows calculation of the expected grain size.

Many materials exhibit a power law relationship between sintering density and sintering time: $:^{18,32,33}$

$$
f=f_{\mathrm{O}}+\alpha t^{N}
$$

where $f_{\mathrm{O}}$ is the starting or green density, $t$ is the time, and $N$ is often near $1 / 6$ to $1 / 3$. The coefficient $\alpha$ includes material properties such as diffusivity and surface energy. Copper sintering data illustrate the trajectory. The sintered density term $\left(\log \left(f-f_{0}\right)\right)$ versus log time agrees with Eq. 7 (correlation of 0.992 ) as illustrated in Fig. $10 .^{16}$ In turn, from the initial conditions, it is possible to predict parameters such as surface area and grain size versus sintering time.

\section{SINTERING TRAJECTORY}

Most powders sinter by a combination of densification and nondensification mechanisms, usually surface diffusion and grain boundary diffusion. Both reduce surface area during bond growth. Surface diffusion is important to early sintering when there is little grain boundary area. Subsequently, grain boundary diffusion produces densification. Depending on the material, various trajectories of surface area versus density result. A few time-temperature experiments help isolate the

\begin{tabular}{|c|c|c|c|}
\hline Grain coordination $\left(N_{\mathbf{C}}\right)$ & Fractional density $(f)$ & Solid-solid contiguity $\left(C_{\mathrm{SS}}\right)$ & Pore size $(d)$ \\
\hline 8 & 0.66 & $1-1.4 \varepsilon^{1 / 2}$ & $0.4 \mathrm{G} \varepsilon^{1 / 2}$ \\
\hline 12 & $0.66-0.89$ & $1-1.5 \varepsilon^{1 / 2}$ & $0.4 \mathrm{G} \varepsilon^{1 / 2}$ \\
\hline 14 & $0.89-0.95$ & $1-1.6 \varepsilon^{1 / 2}$ & $0.4 \mathrm{G} \varepsilon^{1 / 2}$ \\
\hline $14^{\mathrm{a}}$ & $0.95-1.00$ & $1-1.7 \varepsilon^{1 / 2}$ & $0.5 \mathrm{G} \varepsilon^{1 / 3}$ \\
\hline
\end{tabular}

Table I. Geometric relationships between sintering microstructure parameters

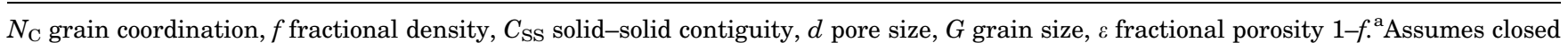
pores. 
grain size, $\mu \mathrm{m}$

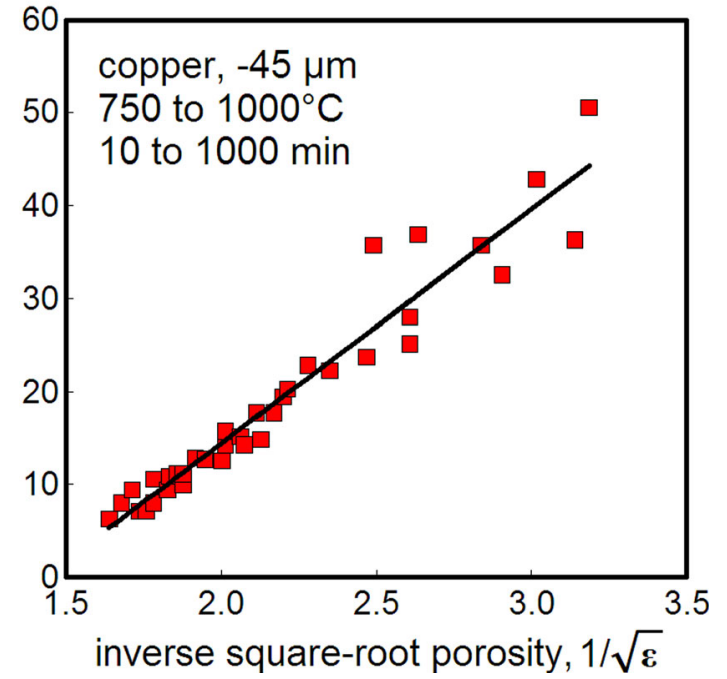

Fig. 8. Copper grain size data ${ }^{16}$ showing sintered grain size versus the inverse square-root of the fractional porosity. ${ }^{27}$

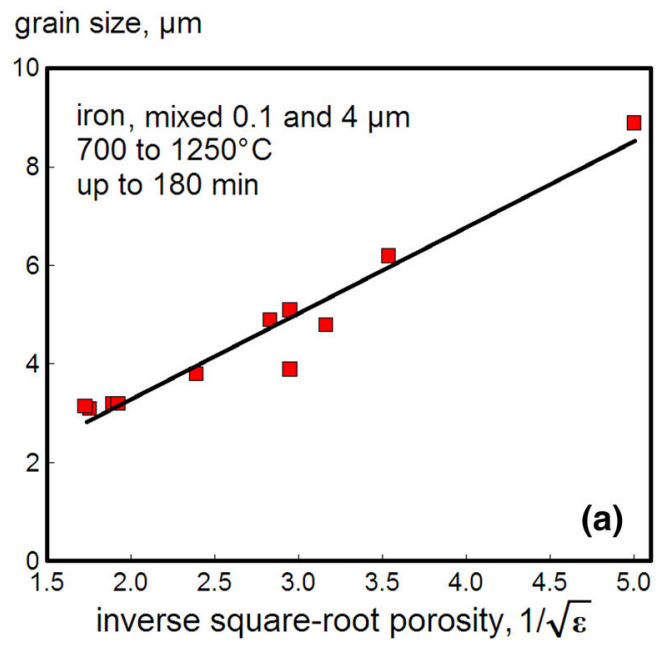

grain size, $\mu \mathrm{m}$

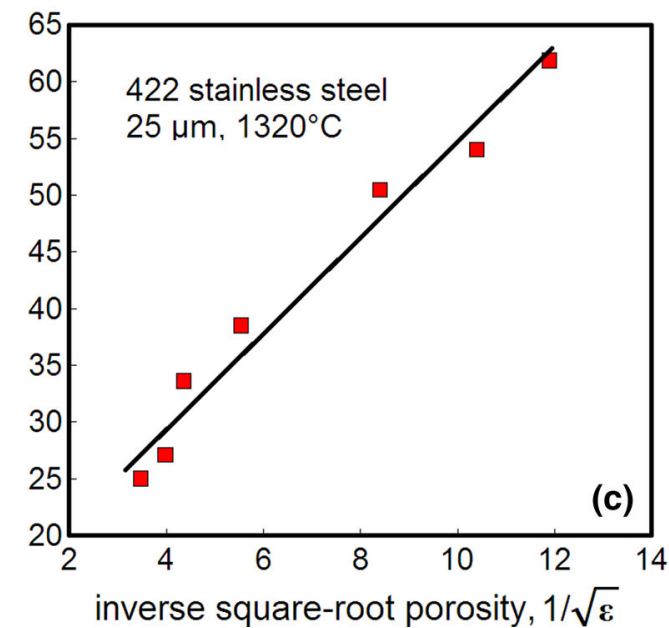

$\log$ (fractional density - initial density)

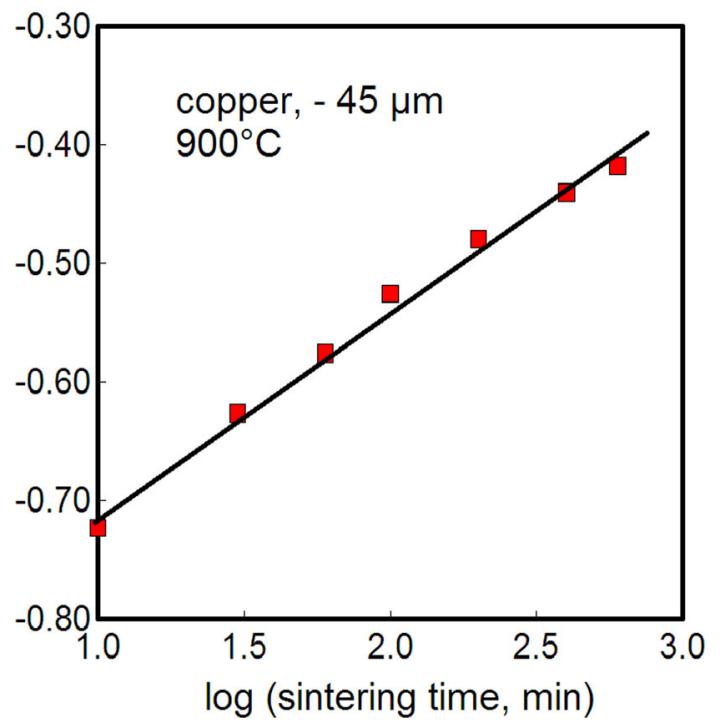

Fig. 10. Sintering density change from the initial value $\left(f-f_{O}\right)$ versus time plotted on a log-log basis using data for copper. ${ }^{16}$

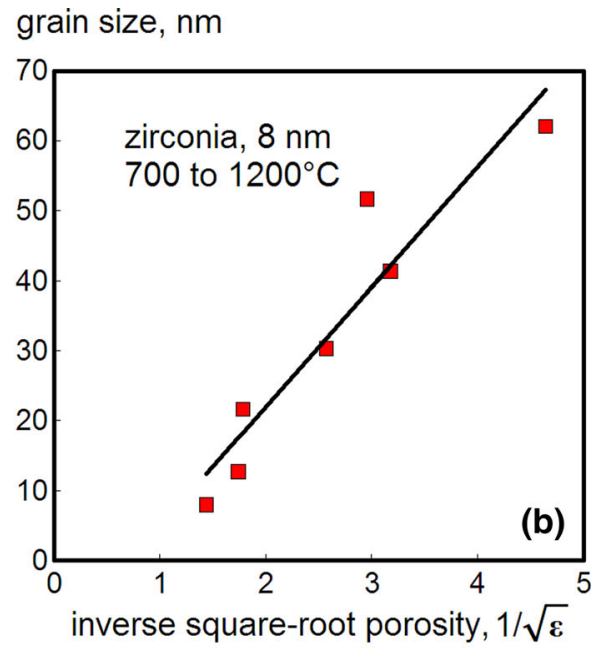

grain size, $\mu \mathrm{m}$

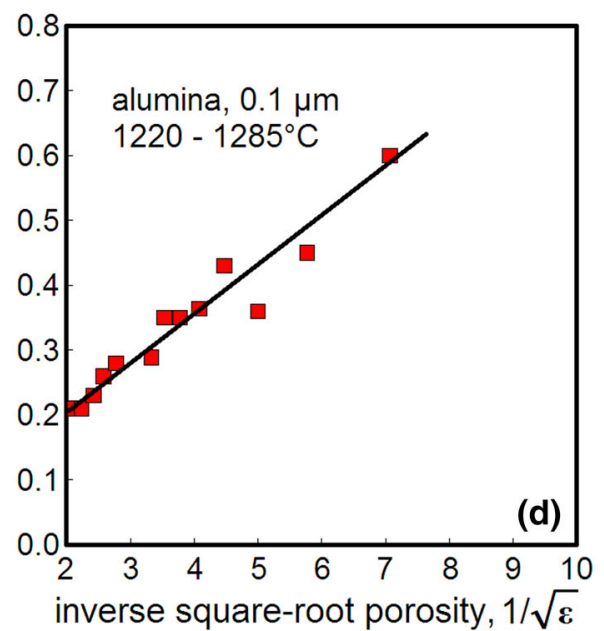

Fig. 9. Grain size versus inverse square-root fractional porosity for iron, ${ }^{28}$ zirconia, $^{29}$ stainless steel, ${ }^{30}$ and alumina. ${ }^{31}$ 
trajectory for density. ${ }^{34}$ In turn, surface area and grain size variations with sintered density are similar over a wide range of materials.

\section{SUMMARY}

Early sintering concepts focused on mass transport mechanisms, particle bonding and the associated shrinkage, densification, and pore structure changes. Computer simulations help track the resulting complex interactions and events. In spite of the complexities, a simple view comes from following energy reduction by surface area loss and subsequently grain boundary loss.

Tracking sintered density is sufficient to estimate many sintering parameters. Sinter density changes with a $\log -\log$ relationships to sintering time. Initially, surface area is eliminated as bonds grow between contacting particles. Grain boundaries form in those bonds to accommodate the crystal orientation difference between grains. Specific surface area decreases linearly as density increases. At the same time, grain boundary area increases, enabling more densification by grain boundary diffusion, but energy reduction drives grain growth and the elimination of grain boundary area. As a consequence grain boundary area peaks near 80 $85 \%$ density. While pores remain, grain size varies with the inverse square-root of fractional porosity. Over a broad array of materials, the sintering trajectories follow a characteristic trajectory, where specific surface area, grain size, and fractional density are related.

\section{ACKNOWLEDGEMENTS}

Prof. Viplava Kumar of Mahatma Gandhi Institute of Technology sparked renewed interest in morphological models for sintering. Funding for research on sintering is provided by the National Aeronautics and Space Administration (NNX14AB31G) under the management of Drs. James Patton Downey and Biliyar Bhat at the Marshall Space Flight Center.

\section{REFERENCES}

1. R.M. German, Sintering from Empirical Observations to Scientific Principles (New York: Elsevier, 2014).

2. D.C. Blaine, S.J. Park, P. Suri, and R.M. German, Metall. Mater. Trans. A 37A, 2827 (2006).
3. Y. Wu, D. Blaine, B. Marx, C. Schlaefer, and R.M. German, Metall. Mater. Trans. A 33A, 2185 (2002).

4. E.H. Aigeltinger and H.E. Exner, Metall. Trans. A 8A, 421 (1977).

5. I. Nettleship, M.D. Lehigh, and R. Sampathkumar, Scr. Mater. 37, 419 (1997).

6. N.J. Shaw and R.J. Brook, J. Am. Ceram. Soc. 69, 107 (1986).

7. K.D. Zilnyk, G.S. Leite, H.R.Z. Sandim, and P.R. Rios, Acta Mater. 61, 5821 (2013).

8. R.M. German, Crit. Rev. Solid State Mater. Sci. 35, 263 (2010).

9. R.T. DeHoff, R.A. Rummel, H.P. LaBuff, and F.N. Rhines, Modern Developments in Powder Metallurgy, vol. 1, ed. H.H. Hausner (Plenum, New York, 1966), p. 310.

10. J. Frenkel, J. Phys. 9, 385 (1945).

11. A.P. Sutton and R.W. Balluffi, Interfaces in Crystalline Materials (Oxford: Clarendon Press, 1995), p. 599.

12. R.M. German, R.W. Mar, and J.C. Hastings, Am. Ceram. Soc. Bull. 54, 178 (1975).

13. M.J. Readey and D.W. Readey, J. Am. Ceram. Soc. 69, 580 (1986).

14. S.H. Hillman and R.M. German, J. Mater. Sci. 27, 2641 (1991).

15. R. Watanabe and Y. Masuda, Trans. Jpn. Inst. Metals 13, 134 (1972).

16. R.L. Coble and T.K. Gupta, Sintering and Related Phenomena, eds. G.C. Kuczynski, N.A. Hooton, and C.F. Gibbon (New York: Gordon and Breach, 1967), p. 423.

17. S.C. Coleman and W. Beere, Phil. Mag. 31, 1403 (1975).

18. R.M. German, Sintering Theory and Practice (New York: Wiley, 1996).

19. W. Beere, J. Mater. Sci. 8, 1717 (1973).

20. J.P. Jernot, M. Coster, and J.L. Chermant, Powder Technol. 30, 21 (1981).

21. S. Prochazka and R.L. Coble, Phys. Sinter. 2, 1 (1970).

22. A.S. Watwe and R.T. DeHoff, Metall. Trans. A 21A, 2935 (1990).

23. T.M. Hare, Sintering Processes, ed. G.C. Kuczynski (New York: Plenum, 1980), p. 77.

24. J.V. Kumar, Solid State Phenom. 8, 125 (1989).

25. P.E. Evans and D.W. Ashall, Int. J. Powder Metall. 1, 32 (1965).

26. R.M. German, Mater. Sci. Forum 835, 50 (2016).

27. C.A. Bruch, Am. Ceram. Soc. Bull. 41, 799 (1962).

28. J.P. Choi, H.G. Lyu, W.S. Lee, and J.S. Lee, Powder Technol. 253, 596 (2014).

29. A. Sturm, U. Betz, G. Scipione, and H. Hahn, Nanostruct. Mater. 11, 651 (1999).

30. C. Toennes and R.M. German, Powder Metall. Int. 24, 151 (1992).

31. G. Bernard-Granger, N. Monchalin, and C. Guizard, Scr. Mater. 57, 137 (2007).

32. R.L. Coble, J. Appl. Phys. 32, 787 (1961).

33. W.D. Kingery and M. Berg, J. Appl. Phys. 26, 1205 (1955).

34. S.J. Park, S.H. Chung, J.M. Martin, J.L. Johnson, and R.M German, Metall. Mater. Trans. A 39A, 2941 (2008). 